\section{VERSIONES CINEMATOGRÁFICAS DEL TEMA FÁUSTICO}

\author{
M. S. Suárez Lafuente \\ Universidad de Oviedo
}

\begin{abstract}
This article intends to follow the development of the Faustian myth through a number of outstanding films in western culture ending with Faust 5.0 by Fura dels Baus. It starts with a brief analysis of the Faust inscribed in literature by Spiess in 1587 and, progressively, implemented by several European authors up to the Manns. The number of literary and filmic Fausts is so large that this article, a work in progress, provides only a few steppingstones, those considered more relevant in the history of the myth. The main characteristics of the legend are kept as the leading structure of this article, considering the fact that those are the moments that attract the attention of writers and directors and, therefore, suffer more modifications. Modifications that follow the philosophical thought and the social changes of the time in which they were written or filmed. Accordingly, contemporary Fausts bear the imprint of the new technologies and the feminist, postmodern, postcolonial or transcultural perspectives of our era.
\end{abstract}

KEY WORDS: Doctor Fausto; J. Spiess; Christopher Marlowe; J. W. von Goethe; Thomas Mann; Klaus Mann; Georges Melies; F. W. Murnau; René Clair; Giacomo Manzini; Istvan Szabo; Sáenz de Heredia; Fura dels Baus.

El Doctor Fausto y su tentador particular, Mefistófeles, constituyen un tema de absoluta vigencia en el mundo artístico occidental, donde lleva presente, desde finales del siglo XVI, en multitud de manifestaciones: teatro, marionetas, poesía, narrativa, opera, música, pintura y cine mudo y sonoro. El desigual duelo entre ambos contendientes toca muy de cerca temas fundamentales para la conciencia humana y sus posibilidades de trascendencia; lo que somos y lo que deseamos ser, la diferencia entre lo que nos atrevemos a pensar y lo que osamos decir, lo que consideramos natural y nuestra actitud ante la existencia o no de lo sobrenatural son ingredientes constitutivos del mito fáustico. Quizás la razón última de su pervivencia sea que Mefistófeles ofrece un camino viable para buscar

\section{FILMIC VERSIONS OF THE FAUSTIAN THEME}

RESUMEN: La leyenda fáustica, en la que el personaje principal vende su alma al diablo por conseguir lo que más anhela en ese momento, se ha convertido, desde su primera publicación en la imprenta de Johann Spiess en 1587, en un tema recurrente en diferentes medios artísticos. En la literatura en todas sus manifestaciones, en pintura, música y cine, diferentes Faustos soñaron con el placer, el conocimiento, la fama, el dinero o el poder, y aprendieron, de manera dramática, que la vida es breve y los logros humanos efímeros. Puesto que la duda primordial de qué hay después de la muerte no puede ser satisfecha, la venta del alma se convierte en una transacción fútil o trágica, según fuera la respuesta, que ningún Fausto llega a dilucidar. Mefistófeles, el mensajero del diablo, no tiene más remedio que convertirse en un mago o en un bufón para distraer a su señor terrenal, para que no piense en temas trascendentales ni se dé cuenta de las limitaciones de su siervo. Durante cuatro siglos, los personajes de esta leyenda se han adaptado a los cambios filosóficos, sociales, políticos y económicos del mundo occidental y a su reflejo en el arte. En las últimas décadas el duelo dialéctico Fausto / Mefistófeles se ha adaptado al desarrollo de la teoría y de la ciencia en nuestra sociedad; así, encontramos feminizaciones del mito, Faustos transculturales, postmodernos y altamente tecnificados. En este artículo contemplamos su transposición al cine, mencionando las películas más significativas en el desarrollo del tema.

PALABRAS CLAVE: Doctor Fausto; J. Spiess; Christopher Marlowe; J. W. von Goethe; Thomas Mann; Klaus Mann; Georges Melies; F. W. Murnau; René Clair; Giacomo Manzini; Istvan Szabo; Sáenz de Heredia; Fura dels Baus.

ayuda en el más allá, cuando se ha perdido toda esperanza sobre este mundo.

Las primeras manifestaciones del Doctor Fausto se dan en literatura en lo que se puede llamar el eje principal de la leyenda, porque han establecido la estructura fundamental del mito y las variaciones que lo hacen reconocible como tal. El editor alemán Johann Spiess publicó en 1587 el libro Historia von Doctor Johann Fausten, basado, pretendidamente, en hechos reales, con la intención de que constituyera una lectura ejemplar para los cristianos. La traducción de este libro llega a las manos del dramaturgo inglés Christopher Marlowe, quien lo convierte en una excelsa obra de teatro, The Tragical History of Doctor Faustus, 
representada en los primeros años de la última década del siglo XVI. La obra de Marlowe sirvió de modelo para todos los Faustos que se escribieron y representaron durante los siglos XVII y XVIII, hasta que Johann Wolfgang von Goethe publicó su Faust, en dos partes, en 1832, en las que introduce modificaciones fundamentales tales como la presencia de Margarita y la salvación del propio Fausto. Ya en el siglo XX, la figura de Fausto se adapta a las consideraciones artísticas, filosóficas o políticas de cada autor, destacándose la novela de Thomas Mann, Doktor Faustus, publicada en 1947.

El desarrollo de estas cuatro obras maestras, pilares del mito fáustico, responde a la relación del género humano con el conocimiento, en momentos diferentes de la historia. Así, la obra publicada por Spiess en la época de la Reforma religiosa expresa su temor ante el hecho de que el mundo desplace a Dios del centro del universo. A lo que el Doctor Fausto de Marlowe opondría, tan sólo unos años más tarde, que el conocimiento no viene sólo de Dios. Goethe, ejemplo insigne del siglo XIX alemán, establece que el conocimiento humano alcanza sus cotas más altas cuando se manifiesta en ideas, orden y acción. Thomas Mann, en pleno auge del Modernismo, postula que la experiencia humana, para ser completa, ha de conocer lo bueno y lo malo, y fundirlo en lo que él Ilama la "cabeza de Jano del arte". El arco temático establecido por estas cuatro obras fundamentales da cabida a la multitud de variaciones fáusticas establecidas en el mundo del arte en los últimos 400 años.

Las manifestaciones fáusticas en la música y en el cine no han modificado la línea argumental básica de la literatura, sino que han aprovechado todas sus posibilidades histriónicas. La estructura más elemental de la leyenda, a la vista del desarrollo del tema en estas cuatro obras principales, se puede definir en los diez puntos siguientes: la personalidad de Fausto al inicio de la obra, el modo en que se le aparece Mefistófeles, los términos en que ambos cierran el pacto, la caracterización de Mefistófeles a lo largo de la obra, el desarrollo posterior de la personalidad de Fausto, los frutos del pacto establecido, la función de Margarita y de Elena de Troya, la naturaleza de la Noche de Walpurgis, los temas secundarios, como el de Wagner, y el final de Fausto. Los temas elementales que subyacen a esta estructura son: la existencia del Bien y del Mal, y si ambos existen, el por qué vendería una persona su alma al diablo, que es la pre- gunta fundamental y la que más riqueza artística genera, las relaciones de poder entre amo y servidor y la función, dentro del mito, del amor de las mujeres.

Los Faustos son, originalmente, buenos o malos. 0 quieren salvar a la humanidad de la enfermedad y el dolor, o quieren beneficiarse ellos mismos del contacto con el maligno y disfrutar de riquezas, fama y mujeres guapas. Los Mefistófeles clásicos son complicados de invocar, mientras que los más contemporáneos aparecen motu propio o responden a una imprecación airada de Fausto, quien, generalmente, se sorprende de su efecto. El pacto, siempre, se rubrica con sangre de Fausto, y suele ser válido durante 24 años, con la muerte de la figura fáustica al final. Las últimas manifestaciones del tema ofrecen, incluso, la posibilidad de una renovación. En las obras clásicas Fausto se condena eternamente, por dudar de Dios y por confiar en el demonio, pero Goethe le salva por su talante innovador en bien de la humanidad y gracias al amor de Margarita (al igual que Doña Inés salvó a Don Juan) y ya, desde este precedente decimonónico, se salvan otras muchas figuras fáusticas por distintos motivos.

Fausto suele quedar desencantado con lo que le ofrece Mefistófeles después de las primeras curaciones espectaculares, o de los descubrimientos científicos más innovadores, pero tal desencanto lo enjuga Mefistófeles con los juegos amorosos de bellas mujeres, que embaucan a Fausto para que crea en su capacidad de seducción y le confieren éxito social. Y es que Mefistófeles se encarga, desde el principio, de que Fausto no se dé cuenta de las limitaciones del demonio; es decir, que el rey del averno no puede contestar a ninguna pregunta del más allá, ni actuar para conseguir el bien de la humanidad. Por eso aturde a Fausto con bromas, con trucos y con amoríos. La mujer fáustica era, al principio, Helena de Troya, bella y etérea, un espejismo histórico; pero Goethe incluye el amor de este mundo con la figura de Margarita, y aunque Fausto, a partir de ese momento, peca más en el sentido cristiano, pues burla la inocencia y la castidad, también aprende a gustar de los placeres terrenales y mortales, y se "humaniza".

La noche de Walpurgis es un motivo histriónico introducido por Goethe que encontró eco en todos los Faustos contemporáneos, pues permite ejemplificar lo que se considera caótico en cada período: carnavales, ferias, manifestaciones, botellones, lugares de disfraz, desenfreno, pecado, etc. 
Los temas secundarios son también muy histriónicos, muy "cinematográficos", y, de nuevo, su impulsor fue Goethe: los amores del propio Mefistófeles, el papel suspicaz del criado Wagner, etc.

Fausto es una figura recurrente en el arte occidental porque representó desde el principio al hombre moderno, insatisfecho con su mortalidad, con su saber finito, que se siente abandonado por las promesas divinas. En la medida que también las mujeres se incorporan a la acción y al mundo del conocimiento surgen Faustinas, y hasta Mefistófelas. El primer ejemplo de feminización del tema data de 1840, año de publicación de la novela La condesa Faustina, de la alemana Ida Hahn-Hahn y, desde entonces, no han cesado de re/escribirse y re/presentarse tales personajes femeninos.

El tema fáustico y sus variaciones se manifiestan en cientos de re/escrituras en toda la literatura occidental, que se multiplican por mil si consideramos aquellas obras que se inspiran en sus temas aunque no lo mencionen explícitamente. Entre los autores más destacados están, entre los clásicos: G. E. Lessing, Von Arnim, J. D. Hoffmann, N. Lenau, Ivan Turgenev, Louise May Alcott o Marie Corelli. En el siglo XX se cuentan, entre otros, Klaus Mann, Dorothy Sayers, Mikhail Bulgakov, Paul Valery, Hermann Hesse, Orson Welles, Jack Kerouac, Lawrence Durrell, Dylan Thomas, Helene Cixous o Vaclav Havel. En español podemos citar a Estanislao del Campo, Amado Alonso, Adolfo Bioy Casares, Sergio Pitol o Vázquez Figueroa.

Un mito tan atractivo por sus múltiples posibilidades de adaptación y tan popular a la vez, de éxito seguro e inextinguible desde finales del siglo XVI, no podía escapar al interés del arte cinematográfico. Hay que tener, además, en cuenta, que el tema había sido, fundamentalmente, representado; bien como obra de teatro, bien en numerosísimas piezas de marionetas en el siglo XIX, sobre todo en los territorios alemanes. Desde 1897 y hasta la Primera Guerra Mundial se filmaron unas 30 versiones de Fausto, basadas, sobre todo, en la obra de Goethe, de la que se privilegian la caracterización del diablo y la historia trágica del amor de Margarita. De uno de los primeros Faustos, rodado por George Albert Smith en 1897, Faust and Mephistopheles, sólo se conservan dos escenas, que duran poco más de un minuto, y son, precisamente, las que corresponden a esos dos momentos: el aspecto de Mefistófeles y la transformación del carácter de Fausto al ver a Margarita. Hasta 1904 se rodaron otras cuatro versiones, de las que no se sabe nada más que el interés de los directores por el tema, debido al potencial que tenía como "cultura de masas", pues despertaba un entusiasmo generalizado entre los espectadores. Mientras que el tema fáustico había transitado, en el campo de la literatura, por la vía de los aspectos religiosos, éticos y morales, sus inicios en el cine resaltaron, comprensiblemente, las posibilidades estéticas y las truculencias visuales de la leyenda.

Georges Mélies rueda tres fragmentos fáusticos en el cambio de siglo (1897, 1898 y 1903). En estos filmes, que rondan los dos minutos, en los que el propio Mélies representa el papel de Mefistófeles, hay una gran profusión de fuego, humo, máscaras diabólicas y mujeres atractivas bailando por doquier. Pero cuando Fausto se acerca al momento de la verdad, cuando tiene que rendir su alma al diablo, se apagan las hogueras y las antorchas, las bailarinas desaparecen y el paisaje se torna baldío, sin vegetación y con formas geométricas, puntiagudas, simulando el rechazo de la naturaleza hacia el pecador. El apoteosis final se concreta en una secuencia de ruinas, supuestamente el alma fáustica, medio engullida por densas nubes negras y un Mefistófeles reinante que, aupado por las insinuantes bailarinas, despliega unas inmensas alas y se convierte en un poderoso murciélago. Esta escena constituye uno de los hitos de la andadura fáustica en el cine, al igual que aqueIla en que Margarita intenta rezar y pedir perdón a Dios por todo el mal que se derivó de su pecado y Mefistófeles, a sus espaldas, desde el atrio, la distrae para que no concrete su oración. Margarita, arrodillada, y Mefistófeles, de pie a sus espaldas, ocupan el centro de la escena y la dividen en dos: el interior de la iglesia, acogedor, iluminado y de tintes cálidos, y el exterior, frío, estático y oscuro; no cabe duda de la opinión del director respecto al tema, si no fuera porque él mismo elige para sí el papel del demonio. Mélies sigue la trama de Goethe respecto al amor de Margarita y le da ya consistencia cinematográfica.

El Faust que marcó la diferencia fue el de F. W. Murnau, rodado en 1926, que es una auténtica obra de arte. Murnau mezcla aspectos del Faust de Spiess y del de Goethe y cambia el final de la leyenda a su antojo: "en él se va desde la versión masculina de Christopher Marlowe y la versión filosófica de Goethe, hasta una versión libre e histriónica que inspiró la ópera escrita por Gounod" (National Board of 
Review of Motion Pictures); porque la película de Murnau está llena de efectos especiales, tomas innovadoras y poses teatrales. Murnau reconoce en el cine el nuevo espacio para la cultura popular, la Cultura, con mayúscula, es válida para el discurso y la letra escrita; él quiere producir cultura, con minúscula, de efectos engañosos, imágenes visuales e ilusiones, no de argumentos y explicaciones prolijo. Posible razón por la cual la película no gustó a las autoridades, que la censuraron por su inmoralidad y por el papel poco viril de Fausto, que deja el protagonismo épico a Gretchen (Margarita) sin explicar por qué actúa de la manera que lo hace. Pero el público sí que apreció el esfuerzo del director, y se reconoció en las masas que sufren, que necesitan apoyo exterior y que son, además, elemento imprescindible, y hasta central, para entender los motivos de Fausto y su peripecia vital.

Las escenas primeras de la película marcan el sentido de la obra: los cuatro jinetes del Apocalipsis (guerra, peste, hambre y enfermedad) se adueñan del paisaje y de la escena, en la que Fausto es una figura patética, un hombre envejecido y vencido, impotente, a pesar de todo su saber, ante el dolor ajeno, extendido por doquier. Acto seguido se plantea el libre albedrío del ser humano: ¿se puede elegir libremente entre el Bien y el Mal? ¿o somos un juguete en las manos de Dios y del Demonio, un mero pretexto en las disputas dialécticas del ángel bueno y el ángel malo? Como buen ejemplo del expresionismo alemán, el Faust de Murnau está lleno de claroscuros, planos diagonales y contrapicados, que acentúan la trascendencia del tema, a la vez que su tenebrismo. Fausto pierde el favor de Dios porque se desespera, desconfía de Él y de sus obras y designios y se vende al diablo, que es un valor inmediato y que responde presto a su llamada: la puesta en escena para su invocación es ya un clásico. Fausto llega solo, si bien la forma deforme de Mefistófeles le acecha constantemente, a una encrucijada de caminos, bajo una luz descolorida y ominosa a la vez, pues, como esta frase, la secuencia está cuajada de contrasentidos que cobran sentido sólo ante la magnitud de lo que está sucediendo allí. Fausto traza un círculo a su alrededor e invoca la ayuda del diablo, libro en mano, enfrentándose a las cuatro direcciones del compás: Fausto se entrega, por tanto, por entero a las fuerzas del mal, y el Mal le acepta con un gran despliegue de meteoros extremos, como cabe esperar. Fausto es devorado por vientos huracanados, una tormenta espectacular y el fuego del círculo que eligió, y es entregado a la voluntad de Mefistófeles para que viva 24 años de placeres antes de ser devuelto a la vorágine que acaba de intuir en esta secuencia.

A partir de Murnau los Faustos se "modernizan", sin por eso perder los efectos especiales. Sí se pierden la fe en Dios y en las masas, y los directores buscan a Fausto como individuo, e incluso, como tal, al propio Mefistófeles, en lo tocante a su personalidad terrenal. También se prima la parte intelectual del mito, que tiende más hacia presupuestos políticos y económicos, frente al histrionismo del Bien y del Mal de las primeras décadas del cine. René Clair, en La belleza del diablo, de 1949, relativiza la importancia del pacto fijándose más en el duelo verbal entre Fausto y Mefistófeles, de poder a poder. La historia de Gretchen constituye un mero episodio en esta trama y el tema fáustico se seculariza. Un Profesor Fausto, recién jubilado y frustrado por no haber conseguido resultados importantes en su trayectoria profesional, es visitado por Mefistófeles, que le ofrece la juventud y, con ella, una segunda oportunidad. Fausto pide a Mefistófeles que le enseñe el futuro antes de firmar ningún pacto con él, y, en esta elaboración de tiempos paralelos, consigue Clair el efecto singular de su película: tenemos un Fausto joven y un Fausto viejo (Gérard Philipe y Michel Simon respectivamente) discutiendo sobre la conveniencia o no de entregar su alma al diablo y sobre el trasfondo moral de los hallazgos científicos que son capaces de llevar a cabo de la mano de Mefisto, hallazgos que, por otra parte, maravillan a la parte científica de estos Faustos.

Otra vuelta de tuerca cinematográfica es que el Fausto anciano (Michel Simon) ejerce de Mefistófeles para el Fausto joven (Gérard Philipe), lo que complica la identidad de ambos de cara al espectador; pero éste es precisamente el propósito intelectual de René Clair, demostrar su teoría de que toda persona tiene una parte fáustica y una parte mefistofélica, y que es imposible deslindar una de la otra. Viendo la película de su vida futura, el profesor queda tan horrorizado al contemplarse anciano, sin el amor de nadie, sin haber conseguido nada serio en el terreno científico, sostenido únicamente por recuerdos de su poder despótico en la madurez de su vida, que le pide a Mefistófeles que, por favor, cambie el guión; a lo que, como siempre, Mefistófeles contesta que no tiene ninguna capacidad real para llevar eso a cabo, él sólo puede ofrecer a sus Faustos el carpe diem, placer aqui y ahora y poco más. La tragedia 
del Fausto de Clair es que las tentaciones de fama, poder y mujeres fueron muy poderosas en un momento dado y el pacto ya había sido sellado con sangre antes de contemplar el desastroso final.

Ya en 1981, Mephisto, de Istvan Szabo, recibe el Óscar a la Mejor Película Extranjera. La obra está basada en la novela del mismo título de Klaus Mann, publicada en 1936, y centrada en la primera época del nazismo en Alemania; en la novela se insinúa que la gloria nazi es el resultado del pacto fáustico y que terminará, mal, como todos los pactos diabólicos. El tema fáustico es eminentemente germánico desde su principio, y el nazismo es una época abonada para dirimir el pacto con el diablo y la naturaleza del Bien y del Mal. No sólo están las novelas de los Mann, padre e hijo, y las películas respectivas, hay muchas otras obras artísticas sobre esa época, entre las que destaca una serie televisiva, rodada en vídeo, Faustus, Faustus, Faustus, basada en la novela del húngaro Laszlo Gyurkó, El bendito viaje del doctor Fausto al infierno, que arranca de 1944, durante la ocupación nazi de Hungría. Su director es Miklos Jancsó y la fecha de estreno, 1984.

El Fausto de Klaus Mann es un mediocre actor de teatro que anhela la fama y que quiere, además, introducir cambios en la escena: su ambición personal es pasar a la historia como actor y como innovador teatral. Aprovechando que la mayor parte de sus compañeros o se fueron del país para no ser cómplices del nazismo o fueron eliminados, Gründgens pacta con las autoridades y alcanza su sueño durante un tiempo. Ésta es una película postmoderna, cuajada de intertextualidad: no sólo es, originalmente, una novela, sino que está inspirada en la vida de un actor de la época. El actor que interpreta a Mefisto en la película, Klaus Maria Brandauer, actúa de Mefistófeles en el Fausto de Goethe que se representa en ella, y lo hace siguiendo la actuación de Emil Janning, conocido actor alemán que hizo de Mefistófeles en la versión de Faust de Murnau. Item más, Gründgens, el actor real en el que se basa la película, interpretó a Mefistófeles en la película Faust, de Peter Gorski, de 1960. Esta acumulación de versiones fáusticas y mefistofélicas, interpretadas por actores de teatro y actores y directores cinematográficos, es una indicación clara de la complejidad de las decisiones personales, de los límites que definen lo que se considera moralmente apropiado o no, y, sin duda, de la atracción que el tema ejerce sobre artistas e intelectuales.
Una novela fundamental para el ciclo es Doktor Faustus, de Thomas Mann, publicada en 1947. Giacomo Manzini realiza, en 1989, en tres partes, una serie con el mismo título para la televisión alemana, en la que sigue con fidelidad la novela de Mann; el resultado es una película tan compleja como la propia novela, si bien sirve su propósito de acercar tal obra maestra a un público más amplio. Mann considera que la humanidad ha establecido variaciones claramente definidas y clasificadas porque sólo así consigue no caer en la locura y mantener el equilibrio en un orden sobre el que ejercer el poder. Pero, como ya intuyera René Clair, cada persona es Fausto y Mefisto a la vez, buena y mala, capaz de las mayores gestas y de las peores depravaciones, capaz de crear arte y de morir en la podredumbre física. Thomas Mann junta en una sola experiencia estas posibilidades y crea un Fausto/Mefisto que no es más aterrador ni desgraciado que los que el arte nos había dado hasta ese momento.

Ni familia, ni amigos, ni amor, ni nación, ni arte están exentos de la pátina del mal, ni son capaces de liberarnos ni resguardarnos de nada; pero el ser humano necesita seleccionar un campo que le confiera la sensación de seguridad necesaria para seguir viviendo. Así, Adrian Leverkühn considera que el amor y la música son las fuerzas más poderosas para transitar por la vida, pero que disfrutar de ambas no es un placer al alcance de los mortales, por eso renuncia al primero por conseguir la maestría en la segunda. En su pacto de 24 años con el diablo, en un acto sexual liberador de ansias y tensiones que le comunica la enfermedad que le llevará a la tumba, Leverkühn rubrica su renuncia a la fertilidad física en aras de la composición musical, porque "el arte ya no es posible sin el fuego infernal". Cada vez que Leverkühn quiere romper el pacto por amor a alguien, a una mujer, a un sobrino al que llega a amar espontánea y desinteresadamente, el demonio se venga y los destruye (hay aquí una referencia clara al monstruo de Frankenstein) y Leverkühn vuelve a quedar a solas con su propia composición musical, que avanza en la misma medida que su enfermedad, la sífilis. La música que lega al mundo es fría y matemática, carente de armonía, es la música adecuada al resultado de un pacto con el diablo y a la Alemania de la época, que había renegado de la esperanza y fraternidad expresada por la novena sinfonía de Beethoven. Donde el Fausto de Goethe se salva, el de Mann se condena, porque el Fausto de éste tiene más características mefistofélicas: es frío e irónico, impersonalmente 
lógico, y parece llevar el mal allí por donde va, a pesar de lo cual duda y sufre como Fausto, lo que le redime como persona y le confiere el ápice de debilidad necesario para convertirse en héroe fáustico.

En la última parte del siglo XX el tema gira ya abiertamente en torno al poder, la fama y el placer, que son las tentaciones del maligno contemporáneo. El abogado del diablo (Taylor Hackford, 1997), protagonizada por Al Pacino y Keanu Reeves, es un buen ejemplo de esto, pues las armas de la tentación son precisamente las mencionadas más arriba. El personaje mefistofélico se llama John Milton, lo que constituye un guiño literario digno de mención, pues fue el poeta inglés John Milton quien describió al Satanás más interesante de la historia de la literatura hasta el siglo XVII como personaje central de El Paraíso perdido. El demonio de esta película hace gala de dejar libertad total a sus víctimas: "yo no hago nada, yo sólo pongo el escenario"; es el propio abogado el que va vendiendo su alma al diablo a plazos, cada vez que defiende a un culpable, tentado por el placer de ganar sobre el contrincante, convirtiéndose en adicto a la adulación pasajera y viendo cómo crece su cuenta bancaria en números astronómicos y absurdos, que le atan cada vez más a la rueda sin solución del dinero por el dinero. Milton / Satán / Mefistófeles se jacta, también, de ser el último humanista, ya que él cree en la gente, Dios no; él conoce a la humanidad y sabe que caerá en las trampas que le tiende, por muy absurdas que parezcan. Dios, en cambio, tiene que estar loco, para creer que la gente le va a seguir sin contrapartidas visibles. La película sigue la estética realista al uso en los Estados Unidos de final del milenio: actores físicamente agradables, narración bien estructurada y planos fáciles de recordar y concatenar, con un ritmo ágil que dispensa a los espectadores una dosis compensada de sobresaltos, inevitables en un film de contenido fáustico.

A las ambiciones contemporáneas une Mefistófeles la perfección física y la eterna juventud cuando se trata de tentar a mujeres, como es el caso en las películas La muerte os sienta tan bien (Robert Zemeckis, 1992) y Vida y amores de una diablesa (Susan Seidelman, 1989). Tres décadas antes, en 1957, Sáenz de Heredia dirige una versión femenina del mito, Faustina, con un reparto digno de mención: María Félix, Fernando Rey y Fernando Fernán Gómez en el papel de un Mefistófeles raquítico y desmañado. Cuando el demonio le envía a la tierra a servir a Faustina, ésta resulta ser una antigua novia que le engañó en su juventud; Mefistófeles ve la ocasión de vengarse de ella, pero la película está hecha en clave de comedia, con enredos e inversiones incluidas, y el burlado vuelve a ser él, constantemente. Curiosamente para la época y para este tipo de cine, si bien Faustina ha de ser, por definición, una mujer mala, artera, sexy y, sobre todo, egoista, deviene en una mujer independiente, activa y segura de sí misma, que se burla de los hombres usando lo que ellos desean: su sexualidad. La obra es una comedia al uso, sin duda, pero, sorprendentemente, una comedia de lectura feminista, en la que la mujer sabe quién es, qué es lo que quiere y cómo conseguirlo. Frente a los Faustos altruistas o interesados, sorprendidos al final de su vida en su confianza en el maligno, se podría decir que la Faustina de Sáenz de Heredia se mueve en el terreno de Mefistófeles, usurpando el habitual trabajo de dirección y montaje de éste respecto a la trayectoria fáustica. No conocemos la intención del director de la obra, pero, en el imaginario de la audiencia española, ver correr a Fernando Rey para que no se le escape la novia y ver a Fernán Gómez ninguneado por una triunfante María Félix constituye una inversión de los roles tradicionales que va más allá de la mera risa fácil de una comedia. En todo caso, esta Faustina de rompe y rasga supuso un hecho aislado en la cinematografía española, donde sí encontramos otros Faustos importantes.

De hecho, va a ser la Fura dels Baus quien deshumanice por completo a Fausto y lo convierta, en Faust 5.0, estrenada como película en 1998, en prisionero de la técnica, de la ciencia y del lenguaje informático. Fausto es ahora un hombre solo, aislado, atemorizado, deshumanizado y fagocitado por su entorno. Cuando se le aparece Mefistófeles y Fausto se presenta: "Soy Fausto, tu igual", al diablo le da un ataque de risa ante tal pretensión. Fausto, como sus predecesores clásicos, como su homónimo en la obra de Thomas Mann, siente "dos almas que luchan en mi pecho", el Bien y el Mal, la Luz y las Tinieblas, lo que se intuye en este film que constituiría la unidad del ser absoluto. Pero como en el mundo contemporáneo estos grandes temas están degradados, porque son considerados ridículos, la Luz es ahora una bombilla raquítica. Lo único que se mantiene aún es el deseo fáustico, porque aparentemente no puede ser erradicado del ser humano, ya que se mantiene incólume desde el Paraíso Terrenal: "Quiero ser como Él", "Quiero detener el Tiempo", expresa todavía este Fausto a/humano. Con la segunda frase se hermana el Fausto 5.0 
con el Fausto original, que, cuatrocientos once años antes, ya había interiorizado como algo esencial y tenebroso el Tempus fugit, que le unía irremisiblemente al diablo.

La propuesta de la Fura dels Baus es diabólica; consiste en que el principio goethiano de que "la acción es la vida" $y$, por tanto, la salvación se convierte ya decididamente en "los placeres son la acción". Puestos a modificar los presupuestos del mito, lo actualizan de una vez por todas y nos conminan a admitir que la práctica de la sociedad contemporánea demuestra que "el placer es la violencia". La ecuación resultante es ahora la siguiente: para comprender (representado secularmente como el árbol edénico del Bien y del Mal) hay que sentir y para sentir hay que ejercer la violencia, solamente entonces sientes que actúas y que vives; no hay vida fuera del ciclo de la violencia. Esta fórmula la desarrolla Mefistófeles en un espectáculo televisivo, el "Mephisto Show, donde tus sueños se hacen realidad", en el que llevan a cabo una encuesta sobre la pregunta fáustica. "¿Por qué venderias tú tu alma al diablo?", donde el énfasis cae con todo su peso sobre la segunda persona del singular. Faust 5.0, que se resuelve en buena parte de la película en un escenario sombrío, de colores fríos y de recursos mínimos de atrezzo, se convierte de pronto en un carnaval televisivo, pletórico de luz, ruido, gente y movimiento, donde el lenguaje se pliega a los actos y los deseos más bajos de la gente, que se lanza, feliz e inconsciente, al abismo de su destrucción como raza pensante. Mefistófeles se ahorra, con su espectáculo, el arduo trabajo de conseguir la firma del pacto. El leit motiv implícito de la obra fáustica de la Fura dels Baus es el pie de uno de los Caprichos de Francisco de Goya: "El sueño de la razón produce monstruos".

Estos apuntes sobre el desarrollo cinematográfico del mito fáustico pueden darnos una idea aproximada de las múltiples posibilidades derivadas de la confrontación entre Fausto y Mefistófeles, que no son sino, al fin y al cabo, meros trasuntos de la consideración humana sobre lo que es bueno y lo que no lo es. Sabine Doering hace un recorrido por la historia del pensamiento occidental y encuentra a Fausto en cada recodo, si bien con la omnipresente limitación que dio lugar, precisamente, al mito:

Fausto puede alertar a la gente como Diógenes, maldecirles como Timón, experimentar la soledad como el Manfred de Byron, bromear con sus iguales como Alcibiades, filosofar como Sócrates, Platón, Aristóteles, o como un escolástico del medievo, como Spinoza o Leibniz, o estar ávido de placeres como una persona de hoy; a veces es un loco, o un iluso teosofista, un pietista, un beato, un cuáquero, un jesuita, un franciscano, un Don Juan o un Casanova; puede ser un señor de la guerra, un poeta, un soñador, un bienaventurado, un luchador por la libertad, en fin, puede serlo todo, lo que quiera, excepto ser Dios (Doering, 1996, 116).
Recibido: 1 de febrero de 2009

Aceptado: 3 de abril de 2009
VERSIONES CINEMATOGRÁFICAS DE FAUSTO EN ORDEN CRONOLÓGICO

1897. George Albert Smith: Faust and Mephistopheles. Reino Unido.

1897. Georges Méliès: Le Cabinet de Mèphistophélès. Francia.

1898. Georges Méliès: La damnation de Faust. Francia.

1900. Edwin S. Porter: Faust and Marguerite. USA.

1903. Georges Méliès: Faust aux enfers. Francia.

1903. Alice Guy: Faust et Méphistophéles. Francia.

1909. Mario Caserini: Faust. Italia.
1909. Edwin S. Porter: Faust. USA.

1910. Emile Cohl: Le tout petit Faust. Francia.

1910. Henri Andréani y David Barnett: Faust. Francia, Reino Unido.

1911. Cecil M. Hepworth: Faust. Reino Unido.

1911. Bill Bumper's Bargain. Adaptación del Faust de Goethe. USA.

1913. Stellan Rye: Der Student von Prag. Alemania.

1922. Gérard Bourgeois: Faust. Francia.

1922. Marcel L'Herbier: Don Juan et Faust. Francia.

1923. Bertram Phillips: Faust. Reino Unido. 
1925. Victor Charpentier y Stéphane Passet: La damnation de Faust. Francia.

1926. F. W. Murnau: Faust. Eine deutsche Volkssage. Alemania.

1932. Howard Higgin: Walpurgis Night. USA.

1935. Artur Robison: Der Student von Prag. Alemania.

1941. Wilhelm Dieterle: The Devil and Daniel Webster. USA.

1943. Jean-Paul Paulin: L'homme qui vendit son âme. Francia.

1949. René Clair: La beaute du diable. Francia.

1949. John Farrow: Alias Nick Beal. USA.

1949. Josef Seiden: Got, mentsch un tayvel.

(Dios, hombre y demonio). Alemania.

1949. Carmine Gallone: La leggenda di Faust. Italia.

1952. Akira Kurosawa: Ikuru. Japón.

1955. Claude Autant-Lara: Marguerite de la Nuit. Francia.

1957. J. L. Sáenz de Heredia: Faustina. España.

1958. George Abbott y Stanley Donen: Damn Yankees. USA.

1960. Peter Gorski: Faust. Alemania.

1964. J. M. Fernández Unsáin: Mi alma por un amor. México.

1966. Ion Popescu-Gopo: Faust XX. Rumanía.

1967. Nevill Coghill \& Richard Burton: Doctor Faustus. Reino Unido.

1967. Ion Popescu-Gopo: Faust XX. Rumanía.

1967. Stanley Donen: Bedazzled (Mephisto 68). Reino Unido.

1968. Luigi Magni: Faustina. Italia.

1968. Gonzalo Suárez: El extraño caso del Doctor Fausto. España.

1971. Paul Wendoks: Mephisto Waltz. Alemania.
1973. Aleksander Petrovic: The Master and Margarita. Yugoslavia.

1974. Louis Pauwels: Président Faust. Francia.

1975. Nina Companeez: Faustino et le bel été. Francia.

1976. Grzegorz Królikiewicz: Faust. Polonia. TV.

1981. Istvan Szabo: Mephisto. Alemania.

1982. Franz Seitz: Doktor Faustus. Alemania.

1984. Miklos Jancsó: Faustus, Faustus, Faustus. Serie TV.

1984. Walter Hill: Crossroads. USA.

1987. Alan Parker: El corazón del Ángel. USA.

1987. Stan Brakhage: Faustfilm: An Opera: Part I. USA.

1988. Stan Brakhage: Faust 3: Candida Albacore. USA.

1988. Stan Brakhage: Faust's Other: An Idyll. USA.

1989. Stan Brakhage: Faust 4. USA.

1989. Giacomo Manzini: Doktor Faustus. Serie TV.

1993. Fraser C. Heston: Needful Things. USA.

1994. Jan Svankmajer: Lekce Faust. (Lección: Faust). República Checa, Francia.

1995. Manoel de Oliveira: Le Couvent. Francia, Portugal.

1996. Eva Bergman: Faust. Suecia. TV.

1997. Taylor Hackford: El abogado del diablo. USA.

1998. Fura dels Baus: Faust 5.0. España.

2000. Brian Yuzna: Faust: Love of the Damned. USA, España.

2000. Harold Ramis: Bedazzled (remake). USA.

2001. Thom Eberhardt: I was a Teenage Faust. Canadá. TV.

2006. Eric Leiser: Faustbook. USA.

\section{BIBLIOGRAFÍA}

Doering, Sabine (1996): "Fraülein Faust. Weibliche Faustgestalten in der deutschen Literatur". Faust. Annäherung an einen Mythos, Frank Möbus (ed.). Wallstein Verlag, Göttingen, 116-132.

Hawkes, David (2007): The Faust Myth. Religion and the Rise of Representation, Palgrave, Macmillan, New York.

Hedges, Inez (2006): Framing Faust: Twentieth-Century Cultural Struggles, Southern Illinois University Press.

Möbus, Frank, ed. (1996): Faust. Annäherung an einen Mythos, Wallstein Verlag, Göttingen.

Suárez Lafuente, M. S. (1981-82): "Historia y tradición en Doctor Faustus de Christopher Marlowe", Archivum, vols. 31-32, 695-706.

Suárez Lafuente, M. S. (1989): "La dualidad fáustica del actor principal en Mephisto de Klaus Mann", Comunicaciones Germánicas, n. ${ }^{\circ}$ 16, 73-82.

Suárez Lafuente, M. S. (1996-97): "Dos siglos de leyenda fáustica: del Volksbuch al Faust de Goethe, Archivum, Homenaje a Emilio Alarcos, vols. 4647, 451-472.

Suárez Lafuente, M. S. (2001): "Las mujeres y el tema fáustico en la literatura", Representar-representarse, ed. Arriaga Flórez y A. Ramírez. Fundación Juan Ramón Jiménez, Moguer, 465474.

Suárez Lafuente, M. S. (2002): "Feminización del tema fáustico: alternativas de poder", Mujer, cultura y comunicación: realidades e imaginarios, ed. Vázquez Medel y Arriaga Flórez. Asociación Andaluza de Semiótica, Sevilla. DVD. 